\title{
DOES ONE SIZE FIT ALL? EXPLORING ASYNCHRONOUS LEARNING IN A MULTICULTURAL ENVIRONMENT
}

\author{
Ken Morse, $P h D$ \\ Waikato Management School, Private Bag 3105, Hamilton, New Zealand \\ Telephone +64-7-858-2599 Fax: + 64-7-838-4352 \\ Email: kmorse@,mngt.waikato.ac.nz
}

\begin{abstract}
Computer-mediated classrooms coupled with heightened emphasis on removing geographic limitations have led to growing dependence on asynchronous learning networks as a delivery medium. An increasingly robust body of literature suggests both positive and negative implications of knowledge delivery using this medium. However, much less is known about the implications of this delivery method relative to the cultural differences which exist in a geographically limitless environment.

Exploratory research from a graduate level course was used to ascertain some of the basic cross cultural issues which may be relevant in this environment. Using cultural context as a separator, twenty four participants evenly split between low context participants and high context participants were polled regarding their experience in the course. The poll addressed a number of key issues finding increasing frequency in the asynchronous learning network literature. Results confirm some of the published benefits as touted in the literature, but identify an additional set of issues for further research and evaluation.
\end{abstract}

\section{KEYWORDS:}

Learning effectiveness, Cross-cultural communication, Cross-cultural learning, Online learning, Elearning, Asynchronous learning networks, Computer-mediated communication

\section{INTRODUCTION}

Over the past decade, the global environment has changed significantly, reducing the importance of both geographical boundaries and temporal limitations on activities in the global village. Simultaneously, computer-mediated communications has become a widely accepted educational delivery medium [1]. Computer-mediated classrooms coupled with heightened emphasis on removing geographic and temporal limitations have led to growing dependence on asynchronous learning networks as an education and training delivery medium.

An increasingly robust body of literature suggests both positive and negative implications of knowledge delivery using this medium. Touted advantages include location and time independence, quality improvements and greater higher order learning. However, drawbacks include technology and linguistic skills difficulties as well as modified participation strategies. Taken in toto, the existing literature concludes a generally positive benefit accrues from this delivery medium.

However, much less is known about the implications of this delivery method relative to the cultural differences which exist in the global village. Perhaps due to their single culture nature, most if not all of 
the anecdotal evidence has ignored the cultural and sub-cultural influences on communication and learning behavior. Using a graduate seminar environment in which the participants are broadly multicultural, this article explores that gap.

A brief review of the benefits and drawbacks of computer-mediated communication delivery, and a brief review of culture as a behavior regulating device are presented, to provide a backdrop for an example of the cross-cultural delivery of computer-mediated communications in a graduate seminar environment. Using this case study, some conclusions are drawn relative to the benefits and drawbacks of asynchronous learning network delivery, followed by suggestions for further research into this as yet poorly investigated area of discovery.

\section{LITERATURE BACKGROUND}

Before discussing the application of computer-mediated communication to a multicultural graduate seminar, a brief review of the literature relevant to the recent explosion of computer mediated communication is presented, followed by a brief treatment of the growing concern for the impact of cultural differences on learning outcomes.

\section{A. Computer-mediated communication:}

Since the revolution of email and the WorldWideWeb in 1994, universities have changed dramatically in pedagogical structure, increasingly embracing computer-mediated communication (CMC) learning and teaching opportunities. These changes are in part driven by the promise that alternative learning environments could provide comparable, even preferable, learning outcomes relative to the pre-1994 models of learning delivery [1]. An increasingly robust body of literature suggests both positive and negative implications of knowledge delivery using this medium.

According to the literature, an asynchronous $\mathrm{CMC}$ environment provides a series of benefits relative to either face-to-face or synchronous computer mediated environments. These benefits include flexibility, participation quality and quantity, communication openness/access and post-participation review/access for reference purposes.

Flexibility: A group member can contribute whenever s/he has a useful input, thus participation is timeindependent and group members are freed from temporal constraints. A supplemental advantage here is the avoidance of some undesirable classroom behaviors such as bidding to speak, discussion domination by the few and contribution interruption. Likewise, group members can contribute wherever they have access to a networked computer, thus group members are freed from geographic constraints, such that participation is also place independent. As a result, computer-mediated communications allow participants to use a wide range of learning styles, addressing an issue of some concern to delivery designers and faculty. Finally, because of the deposit and response nature of computer-mediated communications, multiple threads of a discussion can be pursued simultaneously, without detracting from the general flow of the discussion. There is a reduced tendency for participants to lose concentration on the central issue while pursuing tangential paths of inquiry $[2,3,4,5,6,7$, and 8].

Participation quantity/quality: Computer-mediated groups tend to generate more ideas than their noncomputer-mediated counterparts. Resulting from the self-paced nature of participation, written output (deliverables) are greater in length, detail and completeness than non-computer-mediated groups. Further, because of the group nature of the computer-mediated environment, each group member may focus their 
efforts on that part of the problem/assignment which they feel better qualified to address, contributing to higher quantity and quality of individual output and a qualitatively improved output as well. Asynchronous communication networks tend to promote richer discussions than face-to-face exchanges regarding the same problem/assignment $[2,3,5,6,7,8$, and 9].

Communication openness/access: Computer-mediated communications change the structure of communication from one-to-one (mentor/tutor) or one-to-many (lecture) to a many-to-many structure, providing greater potential information flow. Further, greater amounts of information become available as participants can upload/download information at will, and can take advantage of the ability to browse information at a relatively rapid pace. Additionally, computer-mediated communications improve the potential for peer-to-peer interaction [3, 5, 6, 7, and 10].

Post-participation review/access for reference: Because computer mediated communications reside in virtual space, and discussions are recorded in that space, a transcript is available for review after-the-fact. This provides a potential opportunity to compose after-the-discussion reports/recommendations without loss of content. Further, the ability to pursue multiple threads in a discussion facilitates post-discussion organization of information. Finally, the potential for individualized, instantaneous feedback exists with computer-mediated communications in the learning environment [2, 3, and 6].

However, use of such networks also poses additional challenges to participants working in this computermediated environment. In addition to technology frustrations, these challenges often include coordination difficulties, timing/delay frustration, and skills deficits.

Technology frustrations: To facilitate time and place independence, participants must be able to gain access to the discussion. This raises issues of both hardware and software compatibility, especially if participants are intent on using their own personal equipment to connect to a network, rather than that which is installed in a single laboratory or campus intranet. Further, both hardware and software reliability have the potential to disrupt the computer-mediated communications environment, reducing the stability of the learning environment. For any number of reasons, computer-mediated communication technology is at times unreliable, unresponsive or uncooperative in meeting the expectations of users. From the unanticipated virus to server incompatibility, the examples are endless. It is sufficient to note that these unexpected difficulties can lead to inconvenience, frustration and, if left unaddressed, disillusion with the delivery medium $[3,5,6,7]$.

Coordination: Groups which have not previously worked together tend to select their coordination strategy in an ad hoc manner, based on the constraints of the communication medium relative to the demands of the task, rather than the expected outcome or the objective to be achieved $[2,5,7,8]$.

Timing/delay frustration: In part stemming from the temporal freedom provided by the CMC learning environment, anticipation of rapid response has become a standard participant behavior, only to be frustrated as they wait for replies/responses from other participants who are likewise freed from temporal constraints [5, 6, and 7].

Skills deficits: Because computer-mediated communications is dependant on written communication methods, this places a premium on a wide range of skills which differ significantly from a non-computermediated counterpart, which among others may include typing skills, written language skills, and interpretation skills. To the extent that participants are weaker in these skills than those of oral, group 
communication, those participants tend to be disadvantaged $[5,6,7]$.

In summary, Valenta, Therriault, Dieter and Mrtek [11] provide a comprehensive summary of these advantages and disadvantages. Perhaps best summing this body of literature is the following quote: "In sum, there is an inherent trade-off in the use of asynchronous group support systems for the components of a task. On the one hand, group members can reflect longer about their contributions, can participate when (and where) they choose to, can focus on those parts of the task that they like and can exchange more information. On the other hand, there are coordination problems and delayed participation may frustrate some team members, affecting the group outcomes."[2]

While there have been some interesting passing notices in some of the literature $[3,6]$, missing from this literature is any systematic consideration of the role played by culture in achieving and/or supporting the benefits and drawbacks ascribed to computer-mediated communications delivery. Culture plays a primary role in determining individual behavior patterns, and provides the paradigm by which experience is interpreted, assimilated, and adapted. Thus, cultural differences would seem to play an important role in determining the relative weight of advantages and challenges in a computer-mediated communications learning environment.

\section{B. Cultural differences}

Although there is little consensus across a wide range of disciplines, culture has been alternatively defined as "Shared patterns of behavior" [12], "Systems of shared meaning and understanding" [13] and "... those learned rules of behavior which bound acceptable practice in a group environment" [14]. In an era of increasing globalization, there has been a growing recognition that different societies (cultures) exhibit different behavior characteristics as a result of fundamental societal assumptions. An early effort to examine this difference was published by Kluckhohn and Strodtbeck [15] in which they suggested societies differed in their response to a number of environmental variables including time, space, other groups, etc. About the same time, Inkeles and Levinson [16] proposed a series of relationship variables to identify the characteristics of culture. Following in this tradition, in a study which remains very influential, Hofstede [17] proposed that societies differ along four separate continua which characterize four differing basic social patterns of any culture. In a later work, his analysis was expanded to include a fifth continuum [18]. Since then, an extensive body of literature has been published to expand, specify, measure and operationalize those continua originally suggested by Hofstede [17].

During the two decades since Hofstede's original proposition, a number of alternative schema have been developed to address societal differences. Other major works contribute to clarify the understanding of culture including Adler [19] and Schein [20]. Significantly, Ronen and Shenkar [21] propose a set of clusters of societies based on a series of attitudinal characteristics. In later major research, Trompenaars [22] suggests a series of attitudinal dimensions which characterize different societies. While there is some similarity between the work of Ronen and Shenkar and that of Trompenaars resulting in the ability to "cluster" countries on the basis of various societal characteristics, the differences warrant consideration as separate major contributions to the cultural influence debate.

Much of this literature is based on the concept of national culture - that the nation/state is the defining characteristic of culture. Increasingly, a broad range of research indicates, however, that the nation/state is an artificial, western European concept [23] which bears little resemblance to those characteristics (basic assumptions, values and norms, and behaviors) which actually define culture [14], as stated above. The upshot of the increasingly rich multi-cultural research base is that behavior varies relative to the cultural background of the individual $[24,25]$. For example, New Zealand is a country with nearly two hundred 
years of colonial/post colonial experience in the Western European (British) tradition. Approximately $75 \%$ of the population is directly descendant within this cultural background, with its attendant western cultural traditions. However, more than $14 \%$ of the population traces its cultural roots to the Maori tradition. It is sufficient to note that historically, Maori culture follows the development path of the Pacific Island cultures rather than that of the European cultural stream [26, 27, 28]. Add to that the recent rapid growth in both Pacific Island (5\%) and Asian (6\%) population [29], we thus find that within the nation/state of New Zealand there are at least two different ethnic cultural streams. In contrast, Chinese culture extends to not only the People's Republic of China, but also to Taiwan, and many of the cultural minorities within greater Asian nation/states. In this extended group, Chinese culture has always revered education, and education is seen as a means to social and philosophical improvement $[30,31]$ a stark contrast to both New Zealand cultures. In neither case is the cultural group clearly matched with an existing nation/state, thus, use of the nation/state as a cultural discriminator has increasingly come into question [32].

Ethnicity, rather than nationality indicates cultural background. Defined as "...people who have culture, language, history and traditions in common ..." [32], ethnicity occupies the key role in cultural and educational behavior. Educational systems are culturally specific [33]. Ethnic group (cultural) differences are reflected in learning styles which are based on the modal behaviors of societal learned values [34]. These are influenced by both communication behavior [35, 36, 37] and education systems [38, 39, 40]. Participant cultures - their learned rules of behavior in a group setting - are therefore important to the development of learning interaction and learning achievement. Specifically, one of a number of generally accepted cultural variables differentiates along a continuum between low context and high context cultures [41]. On one end of the continuum, in a low context culture low levels of programmed (mutually understood) information provide context, therefore communication requires a large amount of explicit information to convey meaning [37]; "in low-context communication, the listener knows very little and must be told practically everything" [41]. Practically speaking, these communications have been associated with "contract cultures" that operate on the basis of the unambiguous written word [37, 41]. On the other end of that continuum is a high context culture in which high levels of programmed (mutually understood) information provide context, which require a longer time to program and to interpret in order to convey meaning [37]. "In high-context communication, the listener is already "contextualized" and so does not need to be given much background information." [41]. Likewise, practically speaking these communications have been associated with "relationship cultures" which operate on the basis of personal networks, relationships, and respect $[37,41]$. This distinction is similar to that of Glenn's "associative/abstractive" construct [42, 43], Servaes "direct/indirect" continuum [44, 45] or Hofstede's "individualism/collectivism" dimension [17, 18, 35].

Because computer mediated communications is language (specifically, written word) dependant, it is subject to the constraints of low/high context cultural patterns [46]. As indicated earlier, the role of language is to carry meaning, and interpretation is an integral part of culture. Language is one means of establishing context among participants of a particular culture group. In low context cultures, language must be specific and well defined, to provide the contextual definition in which to interpret the communication. On the other hand, in a high context culture language may be vague, lacking the specificity of the low context culture, as the environment within which communication takes place clarifies the specific meaning of language [36, 41]. Thus language plays a key role in the communication process. A key issue determining the success of computer mediated communication is the encoding/decoding by which that communication is done. Given that computer-mediated communication is a textual (electronic) rather than a visual (face-to-face) medium, meaning must be carried by the language itself rather than relying on the environmental context as the means of communication and/or interpretation. Given this relationship, because the language of communication is English, low context communication is presumed, thus perhaps disadvantaging those whose cultural background relies on high 
context communication. [47, 48, 49]

Coupled with other cultural (behavioral) variables, this contextual difference influences the development of differing approaches to education based on cultural context. As expected, review of the literature relative to learning behaviors [38, 39, 40] reveals a major difference between those in low context cultures as opposed to high context cultures, as summarized in Table 1. Two columns illustrate the dramatic difference between low context education perceptions/expectations on the left and high context education perceptions/expectations on the right. While many of the basic characteristics of modern western education are listed, one key difference of note from the table is the difference in approach to learning as a result of the cultural background. An important difference is the identification of a specific and defined knowledge which can be obtained by diligence of effort, rather than by questioning and exploration. Of telling importance is the Chinese proverb relative to education, which says "diligence overcomes stupidity" [31] which is reflected in the generally high level of effort exhibited by these high context students.

\begin{tabular}{|c|c|}
\hline Low context learning & High context learning \\
\hline $\begin{array}{l}\text { emphasis on learning outcomes (students as } \\
\text { contributors to exploration and/or development): } \\
\text { student centered learning, active learning }\end{array}$ & $\begin{array}{l}\text { emphasis on teaching inputs (students as } \\
\text { recipients and reproducers of material): } \\
\text { all materials provided in class } \\
\text { rigid parameters set in course syllabi } \\
\text { identical syllabi for all students }\end{array}$ \\
\hline $\begin{array}{l}\text { emphasis on attitudinally based "deep" learning: } \\
\text { development of personal skills, and attitudes } \\
\text { toward lifelong learning }\end{array}$ & $\begin{array}{l}\text { content and knowledge based learning: } \\
\text { little emphasis on personal, transferable skills } \\
\text { "diligence overcomes stupidity" = hard work }\end{array}$ \\
\hline $\begin{array}{l}\text { wide variety of learning tools and assessment } \\
\text { instruments: } \\
\text { assessment as feedback instrument } \\
\text { wide range of assessment/feedback tools } \\
\text { (i.e., group assessment, teamwork, } \\
\text { evaluation, etc.) }\end{array}$ & $\begin{array}{l}\text { individual and examination-based assessment: } \\
\text { frequent, regular, highly content specific } \\
\text { assessment; } \\
\text { assessment is focus of learning } \\
\text { assessment identical for all }\end{array}$ \\
\hline $\begin{array}{l}\text { informal lecturer/student relationships: } \\
\text { teacher as guide/facilitator/mentor in } \\
\text { learning process } \\
\text { inherent informality of frequent one- on-one } \\
\text { contact } \\
\text { intergenerational differences evident }\end{array}$ & $\begin{array}{l}\text { formal lecturer/student relationships: } \\
\text { student performance dependent on teacher } \\
\text { knowledge } \\
\text { address by title as a measure of respect (first } \\
\text { name a sign of disrespect) } \\
\text { non-confrontational: accept teacher } \\
\text { knowledge without question (avoid loss } \\
\text { of face) } \\
\text { inherent wisdom in male and/or in older } \\
\text { persons dominates learning }\end{array}$ \\
\hline high student numbers/high contact time: & small group sizes/low contact time: \\
\hline
\end{tabular}




\section{efficient use of teaching resources sought \\ deep teacher/student relationship sought}

[Compiled from: 31, 38, 39, 40]

Table 1: Contrasting Learning Behaviors

It must be acknowledged that the contrast in Table 1 is clear as it relates to differing end points on a continuum. In practice, these differences can be ameliorated by time spent in the alternative cultural context - a major point of a large literature regarding cross-cultural preparation and training $[34,50]$.

Given the above, participants would be expected to bring a developed set of learning skills as a result of prior learning. These skills include a personal and professional conceptual framework, some analytical skills, and some conclusions/opinions as a result of this prior education. Second, each participant brings a set of life skills and experiences which have been accumulated as a result of the development of their individual learning style. In both cases, these skills and experiences would be expected to differ by cultural background. Given appropriate definition, this difference could be used as an analytical discriminator. Specifically, a different interpretation of language between low context and high context cultures would be expected in a computer mediated environment. This would be evident in differing communication behaviors, and in the impressions of those participants which identify with low context rather than high context cultures.

Likewise, differing learning behaviors would be expected in a computer-mediated environment as a result of cultural background. For example, those from low context cultures might be expected to adapt to informality of communication, to respond to alternate forms of assessment, and to use their own initiative to find additional relevant information and to integrate that information on their own. On the other hand, those from high context cultures might expect formal communication to prevail, expect a single definitive or information specific form of assessment and expect to be directed where to obtain supplemental information, which would then be integrated into the body of knowledge for them.

The foregoing clearly develops a linkage between culture (ethnicity), learning behavior and communication modes. Low context individuals, acculturated toward environmentally related learning variables anticipate that their role in learning is to attain some minimum level of competence [41] which to some extent sees these individuals competing on an individual basis against a standard that may grow or change rapidly over time, and perhaps to a lesser degree, with their peers as well. On the other hand, high context individuals are acculturated to adjust their level of effort to a predetermined performance outcome, and therefore look inwardly at self-behavior to achieve a socially acceptable level of excellence, taking the externally determined standard as a given. Thus, their perception is to change or develop the individual to meet the predetermined standard as opposed to pressing the boundary of knowledge, and therefore indirectly influencing development of some higher learning standard. However, a search of relevant literature in fields of anthropology, sociology, education and management reveals no systematic attempt to demonstrate the relationship between culture, culturally-based learning patterns, and computermediated communication [51].

\section{EXPLORATORY CASE STUDY}

To pursue these expectations, exploratory research was conducted using a graduate seminar, wherein written communication through an asynchronous learning network was the only means of participation. That seminar is described next, followed by an analysis of the findings as a result of a distinctly multicultural learning environment. 


\section{A. The context}

To examine the cross-cultural implications of computer-mediated communication, a graduate seminar class was used. The seminar was devoted to discussing the concept of knowledge development and ebusiness in light of technology changes during the decade of the 1990's. Participants engaged in three extended discussions based on previous knowledge and assigned readings. The seminar was sequenced to argue from the general (What is knowledge/a knowledge economy?) to the specific (How have firms responded to the development of this knowledge-based environment?). A primary goal of the seminar, as with most graduate work, was to cause participants to question many of the statements and assumptions which are accepted as common knowledge or the conventional wisdom regarding a particular topic. To this end, participants were provided a pre-determined set of readings prior to the seminar. These readings were arranged by topic area, with the expectation that participants would have read the materials for each topic prior to the discussion of that topic. The expected outcome of this graduate study is a form of metacognition, that is, analysis of conceptual material to evaluate a broad range of perceptions regarding the impact of Information and Communication Technology (ICT) on business behavior and/or business outcomes.

Unlike previous graduate seminars which were held in a classroom using face-to-face discussion, this seminar was conducted entirely online. This computer-mediated seminar replaced a standard three hour face-to-face session with a computer-mediated (asynchronous) discussion of the same topics. The computer mediated content of this seminar was presented in three consecutive discussions, each of three weeks duration. Prior to the first discussion, an introductory face-to-face session ( 3 hours) was used to acquaint seminar members and build a minimal sense of community. This session was also used to demonstrate the basics of the asynchronous communication system, assuming (appropriately, as it turned out) no prior familiarity with computer-mediated communications software. Because of an unexpectedly large enrollment, the participants were then subdivided into three groups of eight participants, each of which simultaneously addressed an identical series of issues. The lecturer was an active participant though not discussion moderator in each discussion, serving primarily as "devil's advocate". A second face-to-face session was held after the first computer-mediated discussion was completed, for the purpose of clarifying some definitions, and introducing some theoretical concepts which had been obviously misunderstood during the first discussion, as well as obtaining some initial student feedback on the overall structure of the course. Then, after a short period devoted to pre-reading, a second, and later, a third discussion were conducted, with participants reassigned to alternate groups in consecutive discussions.

To ensure student participation, a minimum number of online contributions were required, per student, for each discussion. Each of the three discussions covered a temporal length of three weeks, with students required to contribute at least 12 times during that discussion. Further, although students were allowed multiple contributions during any single calendar day, only one contribution per day was applied to the minimum, thus requiring a minimum of twelve days of contact during the 21 day discussion period. For evaluation purposes, and to ensure a certain amount of reflective thinking about the topic and the discussion content, students were required to submit within 24 hours of the end of each discussion a summary which was to identify the key points of the discussion, the key issues raised, and to facilitate reflective learning, their conclusion relative to their preconceptions as a result of the discussion.

At the conclusion of the third discussion, a final face-to-face session was convened, which was used to elicit group feedback, conduct the standardized course evaluation, and assign a further online feedback exercise. Finally, students were invited to visit the lecturer with face-to-face comments, if they thought 
that was appropriate. The results obtained from these feedback instruments are discussed below.

\section{B. Data Collection}

At the midway point of the course, a face-to-face session was used, in which students were asked to provide initial impressions of their experience in the computer mediated discussion. A brainstorming session was used, in groups of four to six participants, to develop lists of advantages and disadvantages they perceived from their early experience. This non-attributable feedback was used to design an end of course questionnaire, which was used to collect both objective demographic data and qualitative opinions from participants. The end of course questionnaire consisted of three parts: the first, a series of demographic responses; the second, a series of comparative ranking responses; the third a series of open ended qualitative responses. The objective data addressed the demographics of the group, including data relative to language skills and ethnicity. The ranking questions were used to solicit opinions of the course relative to both past experience and each participant's individual learning style. The qualitative data, in the form of a series of open ended questions, were used to elicit rich data for subsequent analysis. The exercise was voluntary, and was not used as one of the marked assessment instruments, yet all 24 participants completed the questionnaire.

Participants in this course were self selected as part of the standard university course enrollment process. Demographically, the class consisted of 24 students, of whom 17 were graduate students and 7 were $4^{\text {th }}$ year undergraduate students enrolled in a graduate course as part of a university approved honors program. Age ranged from 20 to 39 years, with the average age at 28 years. Ten of 24 participants were female. Seventeen of the 24 participants were either current undergraduate students (in their final semester) or new graduate students, all without appreciable work experience. The remaining 7 participants had, at one time or another, held full time employment (4 low context and 3 high context participants). Importantly, not one student had previously participated in a computer mediated course.

A key issue arising from the demographic data is the identification of ethnicity (cultural background) which has been problematic in most recent published studies. In line with the increasing recognition of communication and learning as ethnically (culturally) based behaviors, the low/high context continuum in the style of Hall and Hall [41] was adopted, following the lead of several others [50,51]. In line with the supplemental analysis provided by both Ronen and Shenkar [21] and Trompenaars [22], participants were assigned to either a low context cultural group or a high context cultural group. For example, participants from the United States (1), the United Kingdom (1), Australia (1) and New Zealand (9) were identified as low context participants. Conversely, participants from Pakistan (1), the People's Republic of China (5), the Republic of China (2), Singapore (1), Sri Lanka (1) and Thailand (2) were identified as high context participants. Relevant to the issue of multicultural learning, exactly one half $(50 \%)$ of the participants were representative of low context ethnic groups while the remaining half $(50 \%)$ represented high context ethnic groups. The serendipitous enrollment of exactly one half of each group required no context boundary interpretation, and therefore improves the potential accuracy of response differences, despite the relative small absolute number of participants. Conveniently, for all low context participants, English was the primary language of communication, while for all the high context participants English was a secondary language of communication, the primary language of communication being a non-European based language. While in many cases this could be argued as an artificial distinction between individuals, because the medium of communication is written text through a computer network, it was felt that language skill is a relevant difference within this context.

\section{Data Analysis}


From the information provided in the preliminary feedback exercise, the second section of the end of course questionnaire (Appendix) used a series of ranking questions to allow participants to order the importance of several key characteristics of this course. Table 2 summarizes the highest ranked choices.

\begin{tabular}{|c|c|c|c|}
\hline Topical Area & $\begin{array}{l}\text { Respondent } \\
\text { Composite }\end{array}$ & $\begin{array}{l}\text { low context } \\
\text { subgroup }\end{array}$ & $\begin{array}{l}\text { high context } \\
\text { subgroup }\end{array}$ \\
\hline $\begin{array}{l}\text { Advantages over } \\
\text { face-to-face seminar } \\
\text { (rank order) }\end{array}$ & $\begin{array}{l}1 \text { student personal } \\
\text { convenience } \\
2 \text { time to reflect on } \\
\text { others opinions } \\
3 \text { ability to think } \\
\text { about my } \\
\text { contributions }\end{array}$ & $\begin{array}{l}1 \text { student personal } \\
\text { convenience } \\
2 \text { time to reflect on } \\
\text { others opinions } \\
3 \text { ability to think } \\
\text { about my } \\
\text { contributions }\end{array}$ & $\begin{array}{l}1 \text { ability to say things } \\
\text { I think appropriate } \\
2 \text { ability to think } \\
\text { about my } \\
\text { contributions } \\
3 \text { student personal } \\
\text { convenience }\end{array}$ \\
\hline $\begin{array}{l}\text { Disadvantages over } \\
\text { face-to-face seminar } \\
\text { (rank order) }\end{array}$ & $\begin{array}{l}1 \text { difficulty reading } \\
\text { computer material } \\
2 \text { student postings too } \\
\text { long, need a length } \\
\text { limit } \\
3 \text { time consuming to } \\
\text { follow discussion }\end{array}$ & $\begin{array}{l}1 \text { difficulty reading } \\
\text { computer material } \\
2 \text { student postings too } \\
\text { long, need a length } \\
\text { limit } \\
3 \text { time consuming to } \\
\text { follow discussion }\end{array}$ & $\begin{array}{l}1 \text { difficulty reading } \\
\text { computer material } \\
2 \text { student postings too } \\
\text { long, need a length } \\
\text { limit } \\
3 \text { time consuming to } \\
\text { follow discussion }\end{array}$ \\
\hline $\begin{array}{l}\text { Learning, compared } \\
\text { to face-to-face } \\
\text { seminar }\end{array}$ & $\begin{array}{l}1 \text { - significantly more } \\
\text { effective } \\
2 \text { - somewhat more } \\
\text { effective }\end{array}$ & $\begin{array}{l}1 \text { - significantly more } \\
\text { effective } \\
2 \text { - somewhat more } \\
\text { effective } \\
3 \text { - no different }\end{array}$ & $\begin{array}{l}1 \text { - significantly more } \\
\text { effective } \\
2 \text { - somewhat more } \\
\text { effective } \\
3 \text { - somewhat less } \\
\text { effective }\end{array}$ \\
\hline
\end{tabular}

Table 2. Participant perceptions

Firstly, participants were asked to rank what they perceived to be both advantages and disadvantages to participating in a computer mediated discussion seminar. The composite column provides the ranking of all 24 participant responses combined, while the low context and high context subgroups are based on the twelve responses associated with each of those participants respectively. The data clearly indicate that there are significant differences by context group, when context is defined as a cultural characteristic rather. When asked to rank the perceived advantages of the computer-mediated seminar discussion over face-to-face seminar participation, the low context participants invariably ranked personal convenience highest (12 of 12). This reflects an increasing desire to participate in a time and place of their choosing, 
rather than the structured time and place of the face to face seminar. This outcome confirms expectations resultant from the literature review, where flexibility in time and location has been ranked highly as a benefit of computer mediated communication. Remarkably, this is in stark contrast to the high context participants, a majority of whom ( 9 of 12) ranked their ability to say what they thought appropriate as the greatest advantage of computer-mediated seminar discussion. While further investigation is necessary here, this may be due to the relatively structured nature of information in high context cultures, and certainly corresponds with their past learning experiences and behaviors, as indicated in Table 1 .

Secondly, while low context participants perceived as an advantage their ability to reflect on the contributions of others (9 of 12), high context participants more highly valued the ability to think about their own contribution to the computer mediated discussion (8 of 12). It would appear from this ranking that low context participants may be outwardly oriented (what do others think?), while their high context counterparts may be more inwardly oriented (loss of "face"). This result is also consistent with the differing learning expectations identified in Table 1. Coincidentally, this ranking supports previous anecdotal information indicating a self-consciousness regarding language ability, as all high context participants cultural groups primary communication tool (language) was non-European based.

Thirdly, while low context participants unambiguously ranked the ability to think about their own contributions as next most advantageous ( 8 of 12), the high context participants were divided about time to read and reflect on others opinions (5 of 12), ability to follow several issues at once (5 of 12 ), and personal convenience ( 2 of 12). This supports the previous ranking by reinforcing the priority of outward orientation (low context participants) as opposed to inward orientation (high context participants), indicating that the participants responses are internally consistent.

An opportunity was provided for participants to indicate other advantages which they thought deserved consideration, as indicated below:

Low context participants find that the medium:

- introduces new ways of conveying my opinion;

- encourages ability to feel at ease at early stage of graduate development;

- allows individual opinions to not be interrupted by others.

High context participants find that the medium:

- breaks language barriers;

- requires contributions from me every day;

- forces me to read relevant literature.

While there are insufficient data to quantitatively measure the importance of these additional factors, they are nevertheless consistent with the current literature relative to computer mediated communication. Interestingly, low context participants concentrate on the participation environment, while high context participants concentrate on their individual work/effort and/or skills in the discussion. This difference is again consistent with the contrasting learning styles of low and high context participants indicated in Table 1.

On the other hand, when asked to rank order those things participants perceived as challenges associated with computer mediated delivery of a graduate seminar, as Table 2 indicates there was virtually no difference between low and high context participants. Both groups asserted that they found it difficult to read computer material (9 of 12 in each group), although they did not differentiate between assigned course readings and the asynchronous discussion. One supplemental comment, however, suggested that 
the course readings should be provided in printed format, to save participants the time and cost of printing them. They also felt that some participants' contributions to discussions were too long ( 8 of 12 for both groups), which may have been a function of a design failure to suggest a textual limitation for participation. A supplemental comment suggested that some of the discussion contributions appeared to be rhetoric rather than discussion, which may indicate a difference of opinion as to how discussion is conducted - although this issue was not addressed in the questionnaire. And finally, they complained that an excessive time investment was required to participate in this form of course (5 of 12 for low context participants and 7 of 12 for high context participants), although they did not specify what the time commitment was to which they referred.

Likewise, an opportunity was provided for participants to indicate other disadvantages which they thought deserved consideration, as indicated below:

Low context participants:

- some postings not discussion, but rhetoric;

- instantaneous feedback not there;

- impersonal, not conducive to group dynamics.

High context participants:

- research required for participation requires a lot of time;

- must think very hard before I write;

- lack the ability to speak in front of others; does not improve language skills.

Again, although there is insufficient data to quantitatively measure the importance of these additional factors, they are nevertheless consistent with the current literature about computer mediated communication. However, as with the supplemental advantages, low context participants concentrate on the participation environment, while high context participants concentrate on their work/effort and/or personal skills in the discussion. Once again, the difference is consistent with the contrasting learning styles of low and high context participants, as indicated in Table 2.

The third issue addressed in the questionnaire sought participants' opinions regarding the relative contribution of computer mediated discussion to their learning. Reaffirming the predominant theme in the current literature, on this issue there was near unanimity regarding the positive nature of this contribution to their learning as compared to face-to-face discussion. However, bearing in mind that none of the participants had previously engaged in a computer mediated discussion, high context participants were in general more positively inclined to this conclusion than were their low context counterparts, as the high context participants overwhelmingly confirmed that they thought their learning was significantly better as a result of the computer mediated discussion. This result is internally consistent with both the previous questions and the expected performance differences as highlighted in Table 1.

Turning to the subjective questions, two specific issues were addressed in open response fashion. Content analysis was used to develop rich data from the qualitative portions of the post course questionnaire. Two different coders, unfamiliar with either the subject area or the online seminar were used to determine significant content from textual responses, with post coder cross checking revealing an intercoder reliability of .873. A summary of this content analysis follows.

The first textual response question addressed issues of learning and the participants' perception of learning effectiveness of a computer mediated course. The implicit assumption here is that students who had no previous computer-mediated learning experience would draw comparisons with their past 
experiences in face-to-face courses. All 24 students provided written textual response, some of which was extensive. As a result of content analysis, the following issues were prominent in these textual responses.

Consistent with the objective data, the participants unanimously endorsed the asynchronous learning method as a benefit to their learning. All the low context and a quarter of the high context participants reiterated the added convenience of the computer-mediated environment, confirming the results of the earlier objective questions. Several low context participants suggested that, since they were more computer oriented, they felt more comfortable in this learning environment, although this observation was not made by any of the high context participants. On the other hand, because the lecturer was actively involved in the online discussions, the high context participants unanimously identified a closer relationship with the lecturer as a result of the discussions, a positive reinforcement of their previously developed learning styles (Table 1).

Both low and high context participants reiterated their appreciation of the ability to study others contributions offline and reflect on their contribution before further participation. This was a unanimous comment by the high context participants, though only noted by half of the low context participants. Further, high context participants appreciated the ability to work offline to polish the content and meaning of their contributions, reflecting their relative insecurity with both the context and usage of written communication in their second language.

In terms of challenges, all but one of the high context participants identified the difficulty of English language usage compounded by a low level of typing skills. Several noted a distinct improvement in their typing ability as a result of discussion participation. This challenge was not noted at all by the low context participants. Similarly, seven of the twelve high context participants noted the difficulties of exposure to a wide range of new or different computer programs in a short period of time, especially to the extent that these programs were different from those with which they were previously familiar, as a technology/skills challenge. Again, this challenge was not mentioned by the low context participants, indicating perhaps that a greater familiarity with existing campus-wide computer programs and equipment.

Noticeably, high context participants lamented the inability to meet with counterparts, to form social relationships, and to "get to know" the others in the course as both a learning and a social challenge. Not one of the low context participants mentioned this as having either a positive or negative impact on their learning ability. Consistent with the objective data, this result highlights the cultural differences in learning patterns which are impacted by the shift from a face-to-face environment to a computer-mediated communication system.

The second textual response question addressed issues of course organization and the design of a computer mediated course. Again, the implicit assumption here is that students who had no previous computer-mediated learning experience would draw comparisons with their past experience in face-toface courses. Only 22 students provided written textual responses to this question, but conveniently the $50 \% / 50 \%$ ratio was maintained. Perhaps as a result of their positive experience, participants were willing to offer a number of suggestions for improvement, several of which relate directly to responses to the first subjective question, above.

Unanimously, the participants recommended a limitation on the size/length of any one contribution within a discussion. As mentioned earlier, this was most likely a reaction to an original design flaw, which resulted in more than one participant posting lengthy abstracts of essentially news media items to the discussion. 
A second unanimous recommendation was to provide readings in a convenient paper-based format, so they would not have to spend time and money waiting to print the assigned reading articles, all of which were provided in *.pdf format. Three participants commented that reading a computer screen made it difficult for them to make marginal notes, or to highlight material. Neither skill is particularly difficult, and modern word processors easily allow such activities, but the participants were not fully aware of these capabilities, indicating that perhaps there is a skills/training need beyond simply implementing an asynchronous learning network as a transmission/communication mechanism. The strength of this response is consistent with other observations [51, 53], and suggest that differing levels of information and communication technology familiarity is a key issue in course design. Incoming levels of ICT skills are an obvious difference among participants from diverse geographic backgrounds, and is likely to be exacerbated by the diversity of the technological capability found throughout the global community [49].

A third recommendation made by a majority of the high context participants (but mentioned by only one of the low context participants) was that the faculty should promptly respond to student input to take advantage of the immediacy of the communication medium. As an anecdotal illustration, one high context participant became exasperated when, after five hours, there was no faculty response to a direct question, despite the fact that the question had been posed at one o'clock in the morning - indicating that faculty were expected to be available online $24 / 7$, a preconception which is consistent with the expectations of high context students as illustrated in Table 1. Consistent with the literature regarding asynchronous learning networks, the freedom from temporal constraints is an advantage, but it is also a challenge.

\section{Limitations}

All research is beset by limitations, and this exploratory effort is no exception. Without question, the single most constraining limitation is the size of the population which is addressed in this study. For this reason, any conclusions must be tentative in nature, requiring confirmation by a larger and more statistically measurable population. Ameliorating this limitation are the facts that a clear demarcation existed between exact halves of a single population, and that none of the participants had any prior computer mediated communications experience which therefore provides a reliable indicator of possibly widespread underlying differences between cultural groups. However, the results of this exploratory effort do provide some direction for further research in this area, especially in light of the increasingly global dispersion of learning which is facilitated by the growing promulgation of asynchronous learning networks $[47,52]$.

The above analysis presents the perceptions of participants relative to the learning experience, but an alternative question arises: What actual learning has occurred? Although this question is more difficult to answer, and a formal research objective to collect data relevant to this specific issue was not included in the experimental design, some basic analysis can be done using surrogate measures of learning. One potential measure is to compare final course marks with those of past graduate courses taken by the course participants. Of the 24 course participants, 17 had previously completed a graduate course. Of those previous performance data was available for only 13 course participants. Of those, 13 participants, none earned end of course grades below their prior cumulative grade point average. Further, five of the 13 course participants earned an end of course mark which was one or more grades higher (from B+ to Afor example) than their prior graduate grade point average predicted. As this represents just more than half the participants, no correlation of learning experience perceptions to that of actual learning can be inferred, which is thus another limitation to this exploratory case study.

Another difficulty with the foregoing analysis is the extensive reliance on qualitative rather than 
quantitative data. A more rigorous effort, developing statistically measurable hypothesis coupled with a larger population as identified above would go a long way to validating much of the anecdotal information in wide circulation among the asynchronous learning network community.

These limitations can be removed through the conduct of a wider ranging study, with a larger population. However, it is essential that, in any further research effort, the diversity of participant population be maintained, to insure integrity of the resulting conclusions. It is that diversity which provides the value of this particular exploratory analysis.

\section{CONCLUSIONS}

Despite the limitations identified above, this case study indicates that the advantages of asynchronous learning networks carry over from one culture to another, through a range of cultural discriminators. Indicated by this exploratory research, first time participants in a graduate seminar delivered through an asynchronous learning network unanimously perceive higher quality and quantity of learning, as well as greater temporal and geographic convenience, confirming the conclusions of much of the existent literature. Noticeably however, the responses indicate that cultural background directly influences the priority of perceived benefits received and challenges posed from the same asynchronous communication network. The perceptions are based on learning patterns which are developed as part of a participants' ethnic/cultural development, and are potentially challenged by participation in an asynchronous communication network, which of itself is implicitly culturally based. Further, high context participants in an asynchronously delivered seminar, while assured of higher quality participation through an offline ability to infer meaning through low context communications, are at least initially more likely to be disadvantaged by technology differences as well as the communications norms implicit in their cultural background. Finally, this exercise confirms that language differences are important in the perception of effectiveness of asynchronous communications [54]. That the language standard is increasingly English imposes not only a linguistic, but also a cultural burden on the high context culture discussion participant [49].

Pedagogically, the contrast identified in both the theoretical and practical aspects of ethnic/cultural differences in perception highlight a dichotomy of design considerations in developing not only computer-mediated instruction but face-to-face instruction as well. Although some of these differences can be addressed by improving the presentation (graphics, audio, etc.) of existing course content, especially given the many-to-many communication advantages and the peer-to-peer interaction potential of CMC perhaps there also exists an opportunity to develop richer learning through the interaction of all concerned (low context participants, high context participants, education designers) in a broader, transcendent multicultural context. The effort to achieve this will fall squarely on those who design and deliver education.

Despite the exploratory nature of this case study, the results provide clear indications that as globalization continues, culture (and communications) will assume an increasingly important role in the online learning process $[50,51]$. Such indications have important implications for teaching, course design, and learning development [52]. Further, awareness of these differences has practical implications for the future of asynchronous learning - as addressing this variable will allow market segmentation of asynchronous learning, and may lead to improvement in market development in an increasingly wired global village [55].

\section{ACKNOWLEDGEMENTS}


Partial funding for this study was provided by the University of Waikato. The helpful comments and further research directions of three anonymous reviewers are gratefully acknowledged.

\section{REFERENCES}

1. Hiltz, S. R. and Wellman, B. Asynchronous Learning Networks as Virtual Classrooms, Communications of the ACM, vol. 40, no. 9, pp 44-49,1994.

2. Benbaum-Fich, R., Hiltz, R. S., and Turoff, M. A Comparative Content Analysis of Face-to-Face vs. ALN-Mediated Teamwork, Proceedings of the $34^{\text {th }}$ Hawaii International Conference on Systems Sciences, pp 1-10, 2001.

3. Shedletsky, L and Aitken, J. The paradoxes of online academic work, Communication Education, vol. 50, no. 3, pp 206-217, 2001.

4. Jadali, N. Paperless Classrooms, Tech Directions, vol. 59, no. 3, pp 14+, 1999.

5. Althaus, S. (1997). Computer-mediated communication in the university classroom: An experiment with online discussions, Communication Education, vol. 46, no. 3, pp 158-174, 1997.

6. Hiltz, S. R. The Virtual Classroom: Learning without limits via computer networks. $2^{\text {nd }}$ ed. Norwood, NJ: Ablex Publishing Company, 1994.

7. Harasim, L., Ed. Online Education: Perspectives on a new environment. New York: Praeger Publishers, 1990.

8. Rice, R. E. Computer Mediated Communication and Organizational Innovation, Journal of Communication, vol. 37, no. 4, pp 65-94, 1987.

9. Nunamaker, A., Dennis, J., Valacich, J., Vogel, D., and George, J. Electronic Meeting Systems to support group work, Communications of the ACM, vol. 34, no. 7, pp 41-61, 1991.

10. Turoff, M., Hiltz, S. R., Bahgat, A and Rana, A. Distributed Group Support Systems, MIS Quarterly, pp 399-417, December, 1993.

11. Valenta, A., Therriault, D. Dieter, M. and Mrtek, R. Identifying Student Attitudes and Learning Styles in Distance Education, Journal of Asynchronous Learning Networks, vol. 5, no. 2, pp 111-127, September, 2001.

12. Mead, M. Coming of Age in Samoa. New York, NY: Modern Library, 1953.

13. Geertz, C. The Interpretation of Culture. New York, NY: Basic Books, 1973.

14. Groeschel, S. and Doherty, L. Conceptualising Culture, Cross Cultural Management - An International Journal, vol. 7, no. 4, pp 12-17, 2000.

15. Kluckhohn, F. and Strodtbeck, F. Variations in Value Orientations. Evanston, IL: Row, Peterson and Company, 1961.

16. Inkeles, A. and Levinson, D. National Character: The Study of Module Personality and SocioCultural Systems. The Handbook of Social Psychology, $2^{\text {nd }}$ ed. vol. 4, Lindsay, G. and Aronson, E. (eds.) Reading, MA: Addison-Wesley, 1969.

17. Hofstede, G. Culture's Consequence: International Differences in Work-related Values. Newbury Park, CA: Sage, 1980.

18. Hofstede, G. Cultures and Organizations: Software of the Mind. Maidenhead, U.K.: McGraw-Hill, 1991.

19. Adler, N. J. International Dimensions of Organizational Behavior. $2^{\text {nd }}$ ed. Boston, MA: PWS-Kent, 1991.

20. Schein, E. H. Organizational Culture and Leadership. San Francisco, CA: Jossey-Bass, 1985.

21. Ronen, $\mathbf{S}$ and Shenkar, O. Clustering Countries on Attitudinal Dimensions: a review and synthesis. Academy of Management Review, vol. 10, no. 3, pp 435-454, 1985.

22. Trompenaars, F. Riding the Waves of Culture. New York, NY: Irwin, 1993.

23. Chapman, M. Social Anthropology and International Business: Some Suggestions. Paper presented to the Academy of International Business Conference, Brussels, 20-22 November 1992. 
24. Cavusgil, S. and Das, A. Methodological Issues in Cross-cultural Research: A Survey of the Management Literature and a Framework, Management International Review, vol. 37, no. 1, pp 7196, 1997.

25. Lenartowicz, T and Roth, K. A Framework for Culture Assessment, Journal of International Business Studies, vol. 30, no. 4, pp 781-798, 1999.

26. Metge, J. The Maori of New Zealand. London: Routledge, 1976.

27. Pere, R. Ako: Concepts and Learning in the Maori Tradition. Hamilton, NZ: University of Waikato, Department of Sociology, 1982.

28. Bishop, R. and Glynn, T. The development of the pattern of Dominance and Subordination. Chapter 1 in Culture Counts: Changing Power Relations in Education. Palmerston North, NZ: Dunmore Press, 1999.

29. Statistics New Zealand. http://www.statsnz.govt.nz/population/ Wellington, NZ, 2002, accessed 24 March 2002.

30. Naisbitt, J. Megatrends Asia, London: Nicholas Brealey Publishing, 1997.

31. Ming, C. K. The Culture of Schooling in East Asia. Chapter 2.3 in Entwistle, N. (Ed), Handbook of Educational Ideas and Policies. London: Routledge, 1990.

32. Triandis, H. C. The self and social behaviour in differing cultural contexts, Psychological Review, vol. 96, no. 3, pp 506-520, 1989.

33. Terpstra, V. and David, K. The Cultural Environment of International Business. Cincinnati, OH: Southwestern Publishing Co., 1991.

34. Parhizgar, K. D. International Cross-Cultural Collaborative Teaching and Training Theories (ICCCTTT), Journal of Teaching in International Business, vol. 9, no. 3, pp 21-41, 1998.

35. Gundykunst, W. B. and Ting-Toomey, S. Culture and Interpersonal Communication. Newbury Park, CA: Sage, 1988.

36. Gundykunst, W. B. Cultural Variability in Communication: An Introduction, Communication Research, vol. 24, no. 4, pp 327-348, 1997.

37. Korac-Kakabadse, N., Kouzmin, A., Korac-Kakabadse, A. and Savery, L. Low- and HighContext Communication Patterns: Towards mapping cross-cultural encounters, Cross Cultural Management - An International Journal, vol. 8, no. 2, pp 3-24, 2001.

38. Entwistle, N. The Impact of Teaching on Learning Outcomes in Higher Education: A Literature Review. Washington, D. C.: U. S. Gov't Printing Office, 1991.

39. Makepeace, E. Overseas Students - Challenges of Institutional Adjustment. OECD Report on the Internationalization of Education, Standing Conference on Educational Development (SCED) Paper 56, 1996.

40. Maxwell, G., Adam, M., Pooran, J. and Scott, B. Cultural Diversity in Learning: Developing effective learning for South East Asian Hospitality Management Students, Cross Cultural Management - An International Journal, vol. 7, no. 3, pp 3-12, 2000.

41. Hall, E. and Hall, M. Understanding Cultural Differences. New York, NY: Inter-cultural Press, 1990.

42. Glenn, E. Man and Mankind. Norwood, NJ: Ablex Publishing, 1981.

43. Bhagat, R. S., Kedia, B. L., Crawford, S. E. and Kaplan, M.R. Cross-Cultural Issues in Organizational Psychology: Emergent Trends and Directions for Research in the 1990's. Cooper, C. L. and Robertson, T. (Eds). International Review of Industrial and Organizational Psychology: Volume 5, New York, NY: Wiley, 1990, pp 59-99.

44. Servaes, J. Cultural Identity and Modes of Communication. Anderson, J. A. (Ed) Communication Yearbook 12, Newbury Park, CA: Sage, 1989, pp 383-416.

45. Osland, G. E. Doing Business in China: A Framework for Cross-Cultural Understanding, Marketing Intelligence and Planning, vol. 8, no. 4, 1990, pp 4-14.

46. Cifuentes, L. and Yu-chih, D. S. Teaching and Learning online: A collaboration between U.S. and Taiwanese students. Journal of Research on Computing in Education, vol. 33, no. 4, pp 456-474, 2001. 
47. Chan, S.L. Information Technology in Business Processes. Business Process Management Journal, vol. 6, no. 3, pp 224-237, 2000.

48. Cass, K. The World Wide Web's shadow of opportunity: A Heideggerian perspective of authenticity in the information age. Information Technology and People, vol. 11, no. 4, pp 328-337, 1998.

49. Srikantaiah, T. K. and Dong, X. The Internet and its impact on developing countries: examples from China and India. Asian Libraries, vol. 7, no. 9, pp 199-209, 1998.

50. Middleton, $\mathbf{K}$ and Rodgers, J. Communication Across Cultures: Classroom Dilemmas from a Global Perspective, Journal of Teaching in International Business, vol. 11, no. 2, pp 21-37, 1999.

51. Goodfellow, R., Lea, M., Francisco, G. and Mason, R. Opportunity and e-quality: Intercultural and linguistic issues in global online learning, Distance Education, vol. 22, no. 1, pp 65-84, 2001.

52. Mason, R. Globalising Education: Trends and Applications. London: Routledge, 1998.

53. Woolnough, B., Yuyung, G., Leite, M., De Almeida, J., Tae, R., Zhen, W. and Young, D. Factors Affecting Student Choice of Career in Science and Engineering: parallel studies in Australia, Canada, China, England, Japan and Portugal. Research in Science and Ethnological Education, vol. 15, no. 1, pp 105-121, 1997.

54. Brogden, J. and Williams, C. Using advanced communications and multimedia applications to provide real life benefits to remote rural area: BARBARA. Computers in Human Services, vol. 12, no. 1-2, pp 141-150, 1995.

55. Gattiker, U., Perlusz, S. and Bohman, K. Using the Internet for B2B activities: a review and future directions for research. Internet Research: Electronic Networking Applications and Policy, vol 10, no. 2, pp 126-140, 2000.

\section{ABOUT THE AUTHOR}

Ken Morse is a Senior Lecturer of International Management in the Waikato Management School at the University of Waikato in Hamilton, New Zealand. Fifteen years prior teaching in international business at three widely distant U.S. colleges/universities led to his appointment in New Zealand in 1996, where his published research has focused on the pedagogy of international management teaching and the adaptation of technology to the teaching/learning process. Comments and suggestions regarding this article would be greatly appreciated.

Contact: Department of Marketing and International Management, Waikato Management School, University of Waikato, Private Bag 3105, Hamilton, NEW ZEALAND;

Telephone: +64-7-858-2599; Fax: +64-7-838-4532; Email: kmorse@mngt.waikato.ac.nz

\section{APPENDIX}

\section{Item 1 (Table 2, row 1)}

I feel the benefits of conducting online seminar discussions include:

student (personal) convenience

ability to think about my contribution

ability to compose contributions offline, then post

ability to say all the things I think are appropriate

ability to follow several issues at once

time to read and reflect on others opinions

others (list as many as you think are appropriate)

g1 
g2

g3

Of the above list, please list the letters of the three most important, in priority order:

highest second third

Item 2 Table 2, row 2)

I feel the disadvantages of conducting online seminar discussions include:

time consuming to follow discussion

being on campus to use computers

reading computer material

hard to edit my material in online postings

some student postings are too long, need a length limit

each discussion period too short

each discussion period too long

minimum required participation limit too high

others (list as many as you think are appropriate)

i1

i2

i3

Of the above list, please list the letters of the three most important, in priority order:

highest second third

\section{Item 3 (Table 2, row 3)}

Compare to other courses I have taken, the online delivery/discussion was

significantly more effective in helping me to learn

somewhat more effective in helping me to learn

no different in helping me to learn

somewhat less effective in helping me to learn

much less effective in helping me to learn

\section{Objective Questions:}

1. Please comment on your impressions of the impact of this computer mediated course on your learning. What positive effects did it have on your learning? How did the computer based format help you to learn more effectively? At the same time, what negative impacts did it have on your learning? How did the computer based format prevent you from learning more effectively?

2. Would you offer any comments on the organization of the course, and the computer mediated format? What improvements might be mad to help you learn more effectively? What added features might be helpful? Are there components of the course which should be left out? Reduced in scope? 